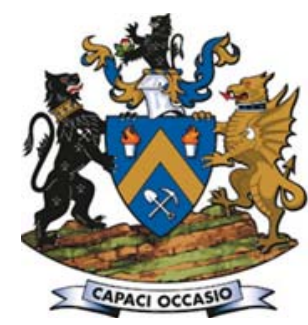

\title{
A critical investigation into tyre life on an iron ore haulage system
}

\author{
by G.C. Lindeque*
}

Paper written on project work carried out in partial fulfilment of B. Eng. (Mining Engineering)

\section{Synopsis}

A downward trend in tyre life on haul trucks at an open pit iron ore mine prompted an investigation into the current tyre management strategy in order to improve tyre life. 'Best practice' was compared to the current tyre management strategy at the mine to determine aspects that could be improved. Aspects that showed significant room for improvement included employee tyre awareness, tyre pressure maintenance, and road conditions. For each of these aspects a plausible alternative was suggested.

A new tyre management strategy was formulated as a step-by-step guide on how to implement the proposed changes. Each step introduces new initiatives but at the same time builds on the previous step's success. A sensitivity analyses was performed to determine the impact of the proposed changes, with the variables being the reduction in the percentage of premature tyre failure, and the reduction of the site wear rate.

The 'most likely' scenario showed an increase in tyre life of $41 \%$ for the Komatsu 730 trucks and $105 \%$ for the CAT 777 trucks if the entire tyre management model is implemented. This would result in a possible annual saving related to tyre usage of $\mathrm{R} 9.2$ million.

Keywords

tyre life, tyre management, wear rate, premature tyre failure, tyre awareness.

\section{Results}

Two main methods of increasing tyre life were identified:

$>$ Method A: reducing the site wear rate of tyres, as measured in millimetres per 1000 hours

$>$ Method B: reducing the percentage of tyres that fail prematurely.

\section{Tyre wear rate}

The most common reason to scrap a tyre is simply because it is worn out. In 2014 it was determined that $59 \%$ of all tyres scrapped were classified as worn out. A tyre that is worn out has reached its maximum life achievable due to a specific wear rate. The wear rate at the mine in terms of each tyre classification is shown in Table II. The data shows that the achievable tyre life for each truck is significantly higher than the recorded tyre life. This is due to abnormal wear of tyres or tyres that fail prematurely.

\section{Premature tyre failure}

In 2014 it was determined that $41 \%$ of all tyres failed prematurely. This is an increase of $8 \%$ from the previous year. The increasing number of tyres that fail prematurely is the biggest contributor to the decreasing trend in tyre life over the last two years. If fewer tyres fail prematurely, more tyres will be worn out and therefore the overall tyre life will be increased. Figure 2 shows the monthly costs associated with each premature failure mode for a period from 2012 to 2014. In November 2014 the year-to-date premature failure cost totalled R2.5 million (Jordaan, 2014), an increase of 92\% from November 2013 (R1.3 million).

The cost associated with tyre failure is based on the value of remaining tread on a

* University of Pretoria, South Africa.

(1) The Southern African Institute of Mining and Metallurgy, 2016. ISSN 2225-6253. Paper received Jan. 2016. 


\section{A critical investigation into tyre life on an iron ore haulage system}

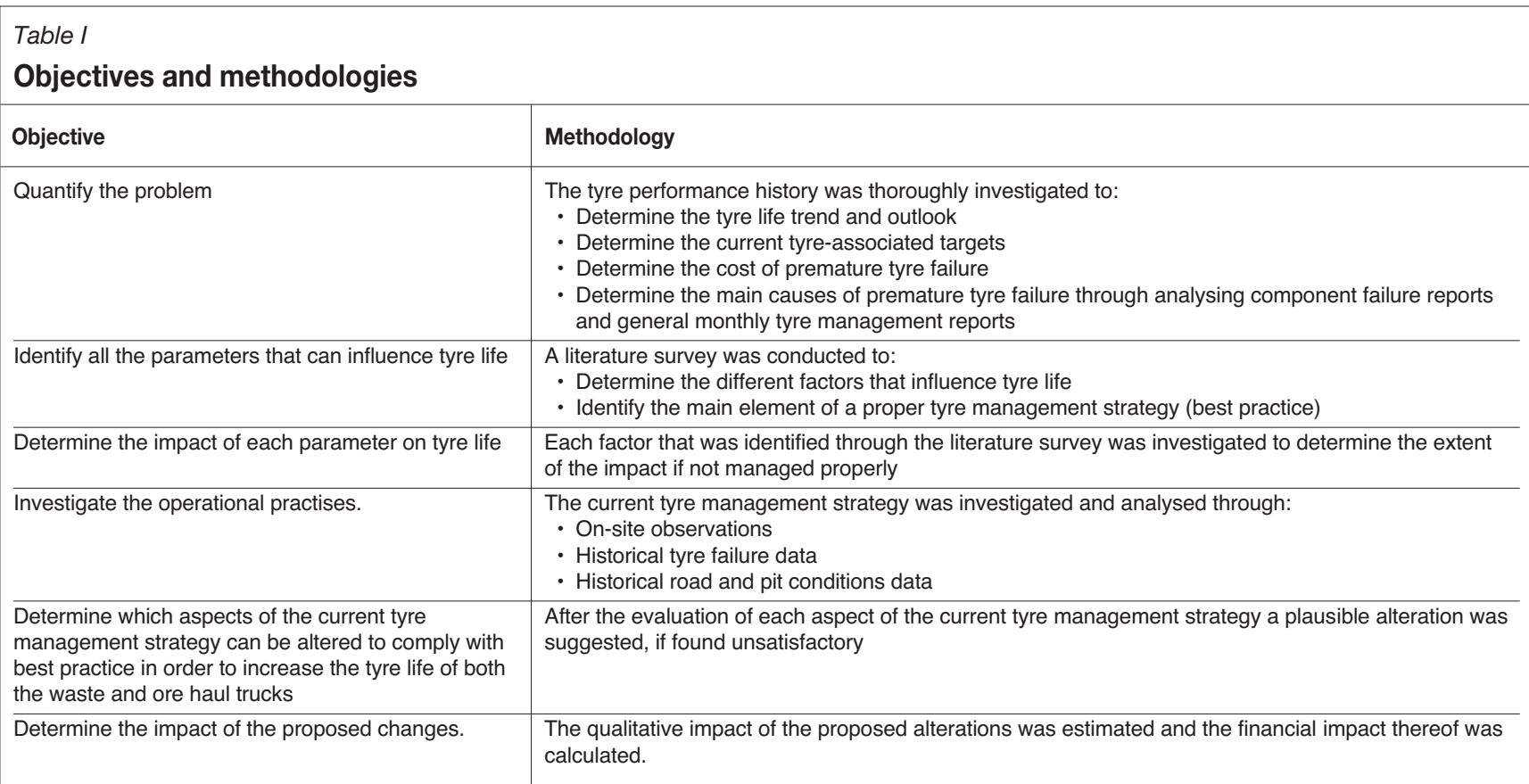

Table II

Tyre wear rate

\begin{tabular}{|c|c|c|c|c|c|c|}
\hline \multirow[t]{2}{*}{ Truck } & \multirow[t]{2}{*}{ Tyre size } & \multirow{2}{*}{$\begin{array}{l}\text { Target tyre life } \\
\text { (hours) }\end{array}$} & \multirow{2}{*}{$\begin{array}{c}\text { Tread available } \\
\text { (mm) }\end{array}$} & \multicolumn{2}{|c|}{ Wear rate $(\mathrm{mm}$ per 1000 hours } & \multirow[t]{2}{*}{ Tyre life at actual wear rate (hours) } \\
\hline & & & & To achieve target tyre life & Actual & \\
\hline $\begin{array}{l}\text { Komatsu } 730 \\
\text { CAT } 777\end{array}$ & $\begin{array}{c}40.00 \times R 57 \\
27.00 \times 49\end{array}$ & $\begin{array}{l}7200 \\
5600\end{array}$ & $\begin{array}{l}87.0 \\
79.0\end{array}$ & $\begin{array}{l}12.1 \\
14.1\end{array}$ & $\begin{array}{l}9.0 \\
8.0\end{array}$ & $\begin{array}{l}9667 \\
9875\end{array}$ \\
\hline
\end{tabular}

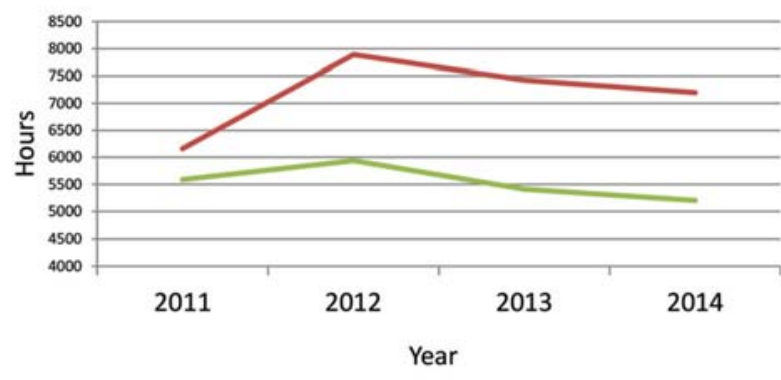

- Komatsu $730 \quad$ CAT 777

Figure 1-Tyre life trends

scrapped tyre, which is referred to as lost tread. The lost tread value of scrapped tyres for 2014 was in the range of R5.5-6.0 million. This is the total value of tread left on all the tyres that were scrapped in the year. Lost tread is caused not only by the various premature failure modes, but also abnormal wear of tyres.

\section{Literature survey}

From the literature survey it was determined that a single tyre failure mode cannot be associated with a certain aspect of tyre management. This led to the conclusion that the entire

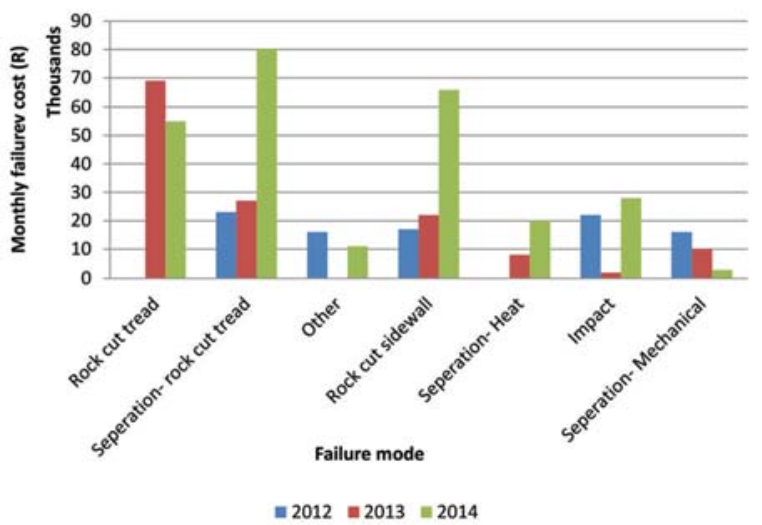

Figure 2-Monthly cost of premature tyre failure

tyre management strategy has to be aligned with 'best practice' in order to significantly improve tyre life. The results from the literature survey suggested that a 'best practice' tyre management strategy should consist of the key elements that are summarized in Table III.

\section{Operational practices}

The operational practices at the mine were then evaluated to determine whether the following elements were adequately addressed. 


\section{A critical investigation into tyre life on an iron ore haulage system}

\begin{tabular}{|c|c|}
\hline \multicolumn{2}{|c|}{$\begin{array}{l}\text { Table III } \\
\text { Key elements of 'best practice' tyre management }\end{array}$} \\
\hline Maintenance & $\begin{array}{l}\text { Tyre pressure maintenance } \\
\text { - Haul road maintenance } \\
\text { Tyre maintenance } \\
\text { - Vehicle maintenance }\end{array}$ \\
\hline Haul road design & $\begin{array}{l}\text { - Horizontal and vertical alignment } \\
\text { - Cross fall } \\
\text { - Drainage } \\
\text { - Super elevation } \\
\text { - Curve radius } \\
\text { - Road construction } \\
\text { - Road width }\end{array}$ \\
\hline Loading practice & The payload policy of the haul truck manufacturer should be strictly adhered to and monitored \\
\hline Vehicle speed & Specific attention to maximum speed, acceleration, and braking \\
\hline Tons-kilometres per hour (TKPH) & The TKPH rating of the tyre should never be exceeded due to the site work load (speed and payload) \\
\hline Matching of tyres & $\begin{array}{l}\text { In order to ensure even wear, tyre assemblies operating as dual pairs must: } \\
\text { - Have the same outside diameter } \\
\text { - Be from the same manufacturer } \\
\text { - Be of the same type (industry code). }\end{array}$ \\
\hline
\end{tabular}

\section{Matching of tyres}

The tyre pairs on the rear axle of a truck need to match in order to ensure even wear of both tyres. The mine does this well, as matching spare tyre pairs are kept in a tyre bank. The tyre bank is kept well stocked by replacing tyres on the front axle after $30 \%$ tread wear with new tyres (Jordaan, 2014). Pairs of equally worn tyres are made up from the replaced tyres and stored in the tyre bank. The mine keeps a well-stocked tyre bank, with 99 Komatsu 730 tyres and 69 CAT 777 tyres recorded during November 2014.

\section{TKPH}

TKPH is a measure of the heat buildup in a tyre due to the load it has to carry and the speed at which it is travelling. The TKPH is currently not being monitored. A TKPH study was done to determine the suitability of the current tyres for the working conditions. The results are summarized in Table IV. The table shows the average TKPH of the tyres on the axle with the heaviest load, thus showing the average maximum TKPH of each cycle. From Table IV it is clear that the actual TKPH for tyre types is well below the TKPH rating of the manufacturer. This suggests that the correct tyres for each truck type in terms of TKPH are being used, and that the tyres are not failing prematurely due to the work load.

\section{Average vehicle speed}

The average vehicle speed is well within the limits prescribed by the mine. There is, however, no means of live monitoring of acceleration and braking. This is where the real danger to tyres lies.

Some elements of the mine's current tyre management strategy showed room for improvement.

\section{Tyre pressure maintenance}

Only $90 \%$ of tyres are correctly inflated at any given time thus 20 tyres in the haul fleet are at an incorrect tyre pressure. To what extent these tyres are incorrectly inflated is unknown. A sensitivity analyses was done and the results were based on the assumption that the $10 \%$ of tyres that are at an incorrect tyre pressure are $90 \%$ inflated. Results would differ if the actual amount of incorrect inflation was known. According to the tyre management contractor (Woodman, 2002), $10 \%$ underinflation in very demanding conditions such as an iron ore mine can lead to a reduction in tyre life of $27 \%$. Another concern is that an individual tyre is only checked seven times per month, and not the minimum required frequency of once a day.

\section{Payload control}

It was found that the mine adheres strictly to the payload policy of Komatsu (2014) in the case of the Komatsu 730 trucks, due to the built-in system on those trucks. This is, however, not the case for the CAT 777 truck. The payload study revealed that only $44 \%$ of all loads were less than the optimum load of $90.5 \mathrm{t}$. Of the $56 \%$ of the loads that exceeded the optimum, $13 \%$ were overloaded more than $20 \%$. This data is summarized in Figure 3.

Table IV

\section{TKPH study results}

\begin{tabular}{|l|c|c|c|}
\hline Truck & Tyre type & TKPH rating & Actual site TKPH \\
\hline Komatsu 730E - 7 & $40.00 \times \mathrm{R} 57$ & 960 & 523.9 \\
Komatsu 730E - 8 & $40.00 \times \mathrm{R} 57$ & 960 & 785.7 \\
CAT 777 & $27.00 \times 49$ & 480 & 386.4 \\
\hline
\end{tabular}

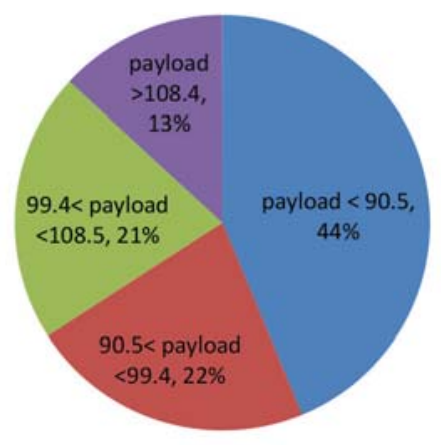

Figure 3-CAT 777 no. 5 payload distribution 


\section{A critical investigation into tyre life on an iron ore haulage system}

\section{Road conditions}

Road conditions can be assessed according to two categories of road - permanent and in-pit. Currently, the permanent roads are monitored and assessed using an assessment and reporting system. This system has a number of drawbacks, the main one being the lack of communication between assessor and operator who can correct the error. A new system is proposed (Dust-a-Side, 2013) that will fill the communication gap. This new system will make continuous road evaluation possible, because road defects can be identified and logged by using a handheld device. This information is immediately shared with the operators of road maintenance equipment by using wireless technology.

\section{Tyre awareness}

The main challenge at the mine is not the tyre management strategy, but the level of tyre awareness amongst employees. Figure 4 show the results of a questionnaire completed by employees of various levels. The employees would have known the correct answers to the questions if their level of tyre awareness was adequate. The most concerning fact is that the operators, who have the largest impact on tyre life, showed the lowest level of tyre awareness.

If tyre awareness increases amongst employees, common operator errors would decrease. These include:

> Reversing onto the muck pile while loading

- Speeding around corners while loaded

> Spillage in the loading area

> Driving through spillage and water

> Incorrect loading practices.

\section{Analysis of results}

The results were reworked into a physical and realistic implementable tyre management model. The model consists of a step-by-step strategy, with different aspect of tyre management to be implemented or changed at specific stages. The model focuses on the three main elements of the current tyre management strategy that showed room for improvement. These are:

> Tyre awareness

> Tyre pressure maintenance

$>$ Road conditions.

The tyre management model consists of three phases. Each phase uses different tools to improve tyre management, but at the same time builds on the previous phase. Table $\mathrm{V}$ describes the initiatives in each phase. It also indicates which tyre life improvement method (A or B) each initiative will have the most significant positive effect on.

\section{Phase 1: Working with people}

The employee mind-set and tyre awareness have to change before large sums of capital are spent on technology in an effort to increase tyre life. Phase 1 consisted of most of the changes to the current tyre management strategy, and thus it was estimated to have the most significant positive impact on tyre life.

\section{Phase 2: Automate information}

Phase 2 is associated with automated information regarding certain aspects of tyre- and road-related elements. This step involves some capital cost and the associated increased operating costs. Phase 2 builds on Phase 1. The initiatives implemented in Phase 1 continue to be practised, with the additional changes described in Table V.

\section{Phase 3: Best Practise}

Phase 3 is the culmination of the tyre management model. This phase involved the majority of the capital spend and has the highest additional operating cost. This step can be implemented only if Phase 1 and 2 were successful.

\section{Sensitivity analysis}

By thoroughly analysing all the results, informed estimations of the cumulative effect of the various initiatives under each phase could be made. A sensitivity analysis was done to determine the impact of different scenarios for each step. These scenarios were classified as 'worst case', 'most likely', and 'best case'. Each of these scenarios is characterized by a different impact of each step on:

> Reducing premature tyre failure (improvement method B)

> Reducing the site wear rate (improvement method A)

This is demonstrated by Table VI.

The results of the sensitivity analysis are shown in Figure 5 by displaying the calculated savings associated with each phase. Phase 1 has the largest positive impact on tyre life and results in the largest possible annual saving. Phases 2 and 3 have a smaller positive impact on tyre life, resulting in less annual saving. This is due to the fact that phases 2 and 3 involve fewer changes to the tyre management system. The better the tyre life on a mine becomes, the harder it is to improve it.

\section{Conclusion and recommendations}

A tyre forum needs to be established at the mine. This forum should include representatives from various divisions of the mine. It is recommended that the tyre forum implement Phase 1 of the tyre management model. The most significant positive impact on tyre life is associated with Phase 1, with an increase in tyre life of $20 \%$ for the Komatsu 730 tyres and $75 \%$ for the CAT 777 tyres according to the 'most likely' scenario. Such an increase in tyre life will reduce the annual tyre usage and result in an annual saving of approximately R6 million.

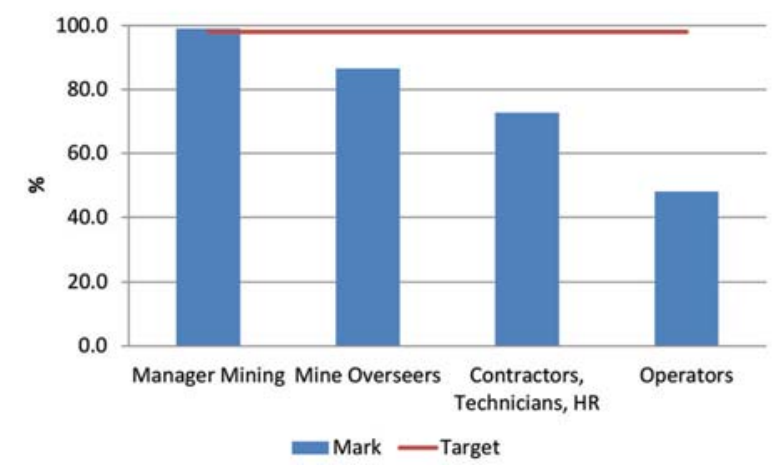

Figure 4-Level of tyre awareness among employees 


\section{A critical investigation into tyre life on an iron ore haulage system}

\begin{tabular}{|c|c|c|c|c|}
\hline \multirow[t]{2}{*}{ Phase } & \multirow[t]{2}{*}{ Initiatives } & \multicolumn{2}{|c|}{ Method } & \multirow[t]{2}{*}{ Description } \\
\hline & & B & A & \\
\hline \multirow[t]{13}{*}{1} & Tyre awareness campaign & \multirow{4}{*}{$\sqrt{ }$} & & $\begin{array}{l}\text { Based on similar tyre awareness campaign results at another mine. Cost based on one full-time } \\
\text { employee salary to drive the programme }\end{array}$ \\
\hline & $\begin{array}{l}\text { Tyre life monitoring } \\
\text { and feedback }\end{array}$ & & & $\begin{array}{l}\text { Work with people, give information but also hold them accountable. Information is distributed using the } \\
\text { current systems and discussed in the daily 09:00 production meeting and during the daily Operator } \\
\text { Caucus sessions }\end{array}$ \\
\hline & Operator education & & & In house (no extra cost) \\
\hline & Incentives & & & $\begin{array}{l}\text { Exact incentive strategy will be designed by a tyre forum but will be based on individual truck tyre } \\
\text { performance. This will single out and reward hard-working employees and will serve as extra motivation } \\
\text { to take good care of tyres }\end{array}$ \\
\hline & Payload control & $\sqrt{ }$ & $\sqrt{ }$ & Only CAT 777 trucks. Payloads will be manually monitored by operators with much more care \\
\hline & Vehicle speed & & $\sqrt{ }$ & Vehicle speed will be manually monitored by all truck operators with much more care \\
\hline & Pressure monitoring & \multirow[b]{2}{*}{$\sqrt{ }$} & \multirow[b]{2}{*}{$\sqrt{ }$} & \multirow[b]{2}{*}{ Increase the number of pressure checks to two per truck per shift. This will require two new employees. } \\
\hline & $\begin{array}{l}\text { Manual pressure checks } \\
(4 \text { per day })\end{array}$ & & & \\
\hline & \multicolumn{3}{|l|}{ Road conditions } & \\
\hline & Site severity survey & & $\sqrt{ }$ & Reinstate the site severity survey as discussed previously. No extra cost \\
\hline & $\begin{array}{l}\text { Specialist grader } \\
\text { operator training }\end{array}$ & & $\sqrt{ }$ & $\begin{array}{l}\text { This requires the training of current grader operators by outside specialist to become specialist graders. } \\
\text { R100 } 000 \text { annual fee converted to a rand per month value. New training and refresher courses would be } \\
\text { needed }\end{array}$ \\
\hline & $\begin{array}{l}\text { Supervisor application } \\
\text { engineering training }\end{array}$ & & $\sqrt{ }$ & $\begin{array}{l}\text { This entails the supervisors of grader operators to be trained by outside specialist in order to become } \\
\text { experts in the field of grading (know what to look at in terms of grader performance, advice to give to } \\
\text { operators, and how to apply the equipment to achieve the best result). R100 } 000 \text { annual fee converted to } \\
\text { a rands per month value. New training and refresher courses would be needed }\end{array}$ \\
\hline & Total impact & $15 \%$ & 0.1 & \\
\hline \multirow[t]{8}{*}{2} & Road conditions & & & \\
\hline & Permanent roads & & $\sqrt{ }$ & $\begin{array}{l}\text { Implementation of the new monitoring system for main haul roads. Capital cost for units and operating } \\
\text { cost for information processing }\end{array}$ \\
\hline & $\begin{array}{l}\text { Grader operator made } \\
\text { higher level status }\end{array}$ & & $\sqrt{ }$ & $\begin{array}{l}\text { Four specialist grader operators are appointed and a new career path is created with the total salary } \\
\text { increased to match that of a haul truck operator. This will ensure that graders are operated only by } \\
\text { grader specialists }\end{array}$ \\
\hline & Pressure monitoring & & & \\
\hline & iTrack for CAT 777 fleet & $\sqrt{ }$ & $\sqrt{ }$ & \multirow{3}{*}{$\begin{array}{l}\text { iTrack TPMS installed for CAT } 777 \text { fleet. Operating cost includes two dedicated employees to monitor } \\
\text { the system. }\end{array}$} \\
\hline & Vehicle speed & & $\sqrt{ }$ & \\
\hline & TKPH monitoring & $\sqrt{ }$ & & \\
\hline & Total impact & $2.5 \%$ & 0.3 & \\
\hline \multirow[t]{7}{*}{3} & Pressure Monitoring & & & \\
\hline & iTrack for entire fleet & $\sqrt{ }$ & $\sqrt{ }$ & \multirow[t]{3}{*}{$\begin{array}{l}\text { iTrack System for entire fleet. Free trial period is available. Operating cost includes three dedicated } \\
\text { employees to monitored and drive the system. Capital cost includes the installation of system on the } \\
\text { remaining } 17 \text { Komatsu } 730 \text { trucks }\end{array}$} \\
\hline & Vehicle speed & $\sqrt{ }$ & $\sqrt{ }$ & \\
\hline & TKPH monitoring & $\sqrt{ }$ & & \\
\hline & Road conditions & & & \\
\hline & $\begin{array}{l}\text { Grader operator made } \\
\text { increased }\end{array}$ & $\sqrt{ }$ & $\sqrt{ }$ & $\begin{array}{l}\text { Six specialist graders operators are appointed and a new career path is created with the total salary } \\
\text { higher level status to match that of a haul truck operator. This will ensure that graders are operated } \\
\text { only by grader specialists }\end{array}$ \\
\hline & Total impact & $2.5 \%$ & 0.1 & \\
\hline
\end{tabular}

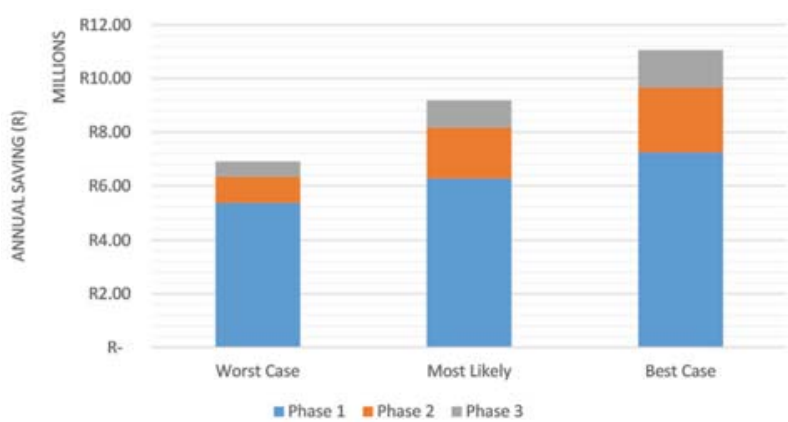




\section{A critical investigation into tyre life on an iron ore haulage system}

\begin{tabular}{l}
\begin{tabular}{l} 
Table VI \\
Sensitivity analysis estimations \\
\hline \multirow{2}{*}{ Phase }
\end{tabular}$\quad$ Tyre life improvement method \\
\cline { 2 - 5 }
\end{tabular}

The main component of Phase 1 is the tyre awareness campaign. The exact details and specifications of this programme need to be designed and driven by the tyre forum to specifically suit the mine. Tyre life improvement needs to be a dynamic and ever-improving process.

Due to the capital sensitivity of the current mining environment, implementation of phases 2 and 3 is optional. The sensitivity analysis showed that the largest opportunity for savings lies with phase 1 , which has virtually no extra cost associated with it.

It is the role of the tyre forum to conduct monthly meetings where the newly formulated tyre management model is discussed and evaluated, focusing on four major areas:

$>$ Conditions

$>$ Operations

> Maintenance

$>$ Tyre performance.

\section{Acknowledgement}

This paper is based on project work carried out in partial fulfilment of the degree B Eng (Mining Engineering)

\section{References}

DUST-A-SIDE. 2013. Dasmetrics introduction and overview. http://www.dustaside.com/services/quality-management-systems/dasmetrics

JoRDAAN, A. 2014. General Monthly Report-November, Mine X: OTRACO International, Redcliffe, Western Australia.

JoRDAAN, T. 2015. Mining Manager. Personal communication.

Komatsu. 2014. About Komatsu. http://www.komatsu.com.au/AboutKomatsu [Accessed 10 December 2014].

Michelin. 2015. Technical Data- Earthmover Tyres.

Woodman, C.A. 2002. Tyre selection, use and operational issues to maximise tyre life. OTRACO International, Redcliffe, Western Australia. 